\title{
An Expansion of the Beneficial Outcomes Associated With the Proactive Employee
}

\author{
Lise Anne Slatten \\ Kerry David Carson \\ David S. Baker \\ Paula Phillips Carson \\ Moody College of Business Administration \\ University of Louisiana at Lafayette \\ Lafayette, Louisiana \\ Author's Notes
}

Correspondence concerning this article should be sent to Lise Anne Slatten, Department of Management, Moody College of Business, University of Louisiana at Lafayette, P O Box 43570, Lafayette, LA 70504. Phone: (337) 482-1184, FAX: (337) 482- 5898. Electronic mail may be sent to las3678@louisiana.edu

\begin{abstract}
The study examined outcomes associated with the proactive individual by analyzing the responses of employees who worked in the health and human services sector primarily providing direct care to patients/clients. Of the 271 respondents, 242 completed the entire online survey which tapped, in addition to proactivity, the constructs of work-group cohesion, compassion satisfaction, burnout, and job withdrawal intentions. While correlations were appraised, the principal analysis of the data was conducted using partial least squares (PLS) path modeling. As predicted the antecedent variable, proactivity, was positively related to work-group cohesion and to compassion satisfaction but negatively related to burnout and job withdrawal intentions.
\end{abstract}

Keywords: proactivity, cohesion, compassion satisfaction, burnout, turnover

\section{Introduction}

When new employees are first hired, managers give individuals a specific job description, and then evaluate them on how well they perform the tasks listed within the document. However, when individuals strictly follow their job descriptions, the inflexibility does not allow for the organization to deal with needed adjustments. This rigidity inhibits employees from helping the organization anticipate and deal with change. The expectation that employees unbendingly follow their job descriptions only works in static conditions, and most organizations are operating in turbulent environments which requires employees to demonstrate flexibility. Given the dynamic nature of business, managers often want employees to go beyond what is required in the job description (Griffin, Neal, \& Parker, 2007). Those employees who willingly pursue broader roles in unstable environments are exhibiting proactivity.

Proactive employees are self-motivated and seek out opportunities to help the organization (Crant, 2000). They typically start by challenging the status quo and voicing their concerns about a problem that needs to be solved or prevented (Morrison \& Milliken, 2000). To convince the supervisor of 
their concerns, they use facts and logic, but they also sell their ideas enthusiastically so that managers will re-think their position and go along with their plans (Crant, 2000; Dutton, Ashford, O'Neill, \& Lawrence, 2001). When taking charge of the project (Morrison \& Phelps, 1999), they set action-oriented objectives and persevere in the face of obstacles (Frese, Fay, Hilburger, Leng, \& Tag, 1997). The behaviors of these proactive employees result in many constructive consequences. In this study, the outcomes examined are work-cohesion, compassion satisfaction, burnout, and job withdrawal intentions.

Many researchers approach proactivity as a personality trait and view these employees as engaging in proactive behaviors acts within and across situations (Bateman \& Crant, 1993; Grant, Gino, \& Hofmann, 2011). Because of the dispositional nature of proactivity, it represents a stable characteristic of the individual. Thus, it is easier to hire employees who exhibit these attributes than attempt to train them to be proactive (Parker, Williams, \& Turner, 2006). Managers need to recruit proactive individuals so they can help identify issues facing the organization. These employees actively create the work environment so that an organization can adapt to the threats that are bombarding it both internally and externally. Some of these threats include uncertain environments; less funding with expectations that services remain at the same level; reductions in force; top management turnover; technological innovation; increasing expectations from customers, clients and patients; and loss of key personnel (Griffin, et al., 2007).

There are many wide ranging effects associated with proactivity. Crant (1995) examined job performance of real estate agents and found that proactive personality significantly contributed to high job performance. This finding on performance was supported in a comparative meta-analysis article which also reported that proactive employees tend to be highly satisfied (Thomas, Whitman, \& Viswesvaran, 2010). They are more satisfied with their jobs because they actively craft their work environment by changing the negative aspects of their workplace that displease them (Bateman \& Crant, 1993; Erdogan \& Bauer, 2005). They also operate autonomously and pursue tasks that are significant to them which, according to the job enrichment model, increases job satisfaction (Hackman \& Oldham, 1975).

They choose and influence the workplace so that there is a good person-organization fit (Seibert, Kraimer, \& Crant, 2001). This fit allows them to identify with and be more involved with the organization which results in high organizational commitment (Thomas et al., 2010). Also, because proactive employees actively change aspects of their lives that they don't like, they are less stressed than others who are more passive (Crant, 1995). Further, when they define their life goals and set out to accomplish them, they meet their psychological needs. This makes them feel good and so they express high satisfaction with life in general (Greguras \& Diefendorff, 2010).

Because proactive employees have reputations for being competent, they have increased opportunities for social networking which is important for achieving their goals (Thomas et al., 2010). They recognize that they must cooperate with others in order to accomplish their objectives because of the interdependent nature of work. They understand that team members need to work with each other in order to get the job done, so they support the work group in completing their tasks even in trying times (Grant, Parker, \& Collins, 2009). Because proactive employees are planners, they engage in anticipatory helping of other team members. They don't just respond to requests from other employees, but rather seek out opportunities to assist others making them high on organizational citizenship behaviors (Greguras \& Diefendorff, 2010). This increases the effectiveness of the work group, as well as, the overall organization (Griffin et al., 2007).

\section{Hypothesis Development}

Proactive individuals seek to create a social environment that will make them more successful in their change efforts so they establish connections with others, taking advantage of the fact that proactivity and job performance is mediated by the individual's networking building (Thompson, 2005). By establishing relationships with peers, these individuals gather information and feedback so they can be more proactive (Thomas, et al., 2010). In order to develop these purposeful networks, they connect with 
others by being helpful (Greguras \& Diefendorff, 2010). This cooperative engagement in organizational citizenship behaviors is positively related to group cohesion (Kidwell, Mossholder, \& Bennett, 1997).

The historical roots of work-group cohesion were introduced by Elton Mayo and Fritz Roethlisberger in the famous Hawthorne studies that took place in a Western Electric Company in Chicago (Vaill, 2007). Cohesion is defined as the degree that group members are attracted to each other and work together to pursue their objectives. It deals with friendships in the immediate team. Those employees who feel that their work-group members are nice and helpful are expressing cohesion. They look forward to interacting with the group members and believe that the members take a personal interest in them (Price, 1997).

When individual group members engage in helping behaviors, there is the development of cooperative group norms (Ng \& Van Dyne, 2005). With consistency of proactive behavioral modeling by just one supportive individual, there can be a prosocial impact on other members (Grant \& Patil, 2012; Shamir, 1990). The socially responsible individual becomes a role model for others for exhibiting organizational citizenship behaviors (Stroebe \& Frey, 1992). While one proactive individual cannot singlehandedly increase group unity, additional cooperative efforts of other members can influence cohesion. As the number of members engaging in organizational citizenship behaviors becomes greater, group cohesion increases (Kidwell et al., 1997).

Cohesive teams disagree with each other as much as non-cohesive teams (van Woerkom \& Sanders, 2010) so proactive employees don't need to agree with team members but they do need to share information with each other. Members who discuss issues with each other are more motivated to accomplish group goals as compared to those who don't. This interaction results in individuals who are emotionally attached to each other and have a collective belief that they can execute their objectives. These cohesive groups are unified and committed to the accomplishments of the group (Shin \& Choi, 2010).

Because they build reputations as individuals who can get things done, proactive employees are valued by others. This cognitive trust results in organizational support, making them more able to voice their concerns and modify the work environment (Thomas et al., 2010). The proactive employee's high organizational status further promotes increased cooperation and trust among peers (e.g., Loh, Smith \& Restubog, 2010). This trust strengthens work-group cohesion (Mach, Dolan, \& Tzafrir, 2010).

Because proactive employees can get things done and have good organizational reputations, they share information with and develop trusting relationships among team members which helps facilitate cooperative group norms, so the following is predicted:

Hypothesis 1: Proactivity is positively associated with work-group cohesion.

While cohesive groups can be socially rewarding, employees also can be interpersonally fulfilled through their compassionate work with others. Individuals who are compassionate show concern for others, empathize with them, and have interest in their welfare. Employees can experience high levels of compassion satisfaction from the pleasure derived from performing well. There is a sense of achievement from having a positive impact on the lives of clients, customers or patients (Stamm, 2005). However, there also is a harmful side to employees displaying compassion at work (Slatten, Carson, \& Carson, 2011). That negative side is compassion fatigue. Compassion fatigue results from dissatisfaction and the inability to do anything about the stressors in the work environment (Radey \& Figley, 2007).

Fortunately, proactive individuals seem unlikely to experience compassion fatigue but rather feel compassion satisfaction. Proactive employees assert themselves and competently change parts of their work environments that are stressful and dissatisfying (Erdogan \& Bauer, 2005 ). They are good at minimizing chronic stress and even preventing stress before it happens as they often recognize a potentially distressing situation. They then use feedback from others to understand and mitigate the stressor (Crant, 1995).

Proactive employees develop supportive group interactions which increase compassion satisfaction (Keidel, 2002). Also, proactive workers enrich their jobs through increased autonomy and 
task significance resulting in higher job satisfaction (Thomas et al., 2010), and those who are high on job satisfaction tend to express higher compassion satisfaction (Lawson \& Meyers, 2011). Finally, proactive individuals are high on self-efficacy (Ohly \& Fritz, 2007) which is also positively related to compassion satisfaction (Prati, Pietrantoni, \& Cicognani, 2010).

Because of their efficacy, supportive relationships, low stress and high job satisfaction, it is predicted that proactive individuals will also express high compassion satisfaction.

\section{Hypothesis 2: Proactivity is positively associated with compassion satisfaction.}

Burnout is a three-dimensional construct consisting of emotional exhaustion, depersonalization of another, and feelings of low personal accomplishment. Emotional exhaustion occurs when an employee is worn out and overextended at work. Depersonalization of clients is a defense mechanism to protect the employee from further exhaustion by treating others like objects instead of human beings. With feelings of low personal accomplishment, employees express hopelessness in making positive changes on the job (Maslach, 1982). Often younger, more idealistic employees are susceptible to burnout. They start out hoping to change the world, but burnout gradually builds over time. This can be caused by many factors at work such as large case loads, overwhelming paperwork, insensitive management, shortages of personnel and role conflicts (Slatten et al., 2011).

Rather than being overwhelmed by negative factors at work, proactive employees are determined to change their conditions. They are high on self-efficacy and confident in their execution of their broad roles. They exert control over how well they function and can maneuver through difficult demands (Ohly \& Fritz, 2007). Self-efficacy has been reported to be negatively related to burnout (Prati et al., 2010), particularly with the emotional exhaustion component (Petitta \& Vecchione, 2011). Further, efficacy and competence result in high organization-based self esteem where employees feel like worthy and valuable members of the organization (Pierce, Gardner, Cummings, \& Dunham, 1989). Organization-based self esteem has been found to be negatively related to all three components of burnout (David \& Vivek, 2012).

Burnout is negatively associated with performance as it reduces both in-role performance (Maslach \& Jackson, 1984) and extra-role performance or organizational citizenship behaviors (Akbar Ahmadi, Ahmadi, \& Tavreh, 2011; Petitta \& Vecchione, 2011). In contrast, proactivity is positively associated with both of these outcomes. Proactive individuals have high in-role performance for two primary reasons. First, they select situations that will improve the likelihood that they will perform well. Secondly, they actively modify their situations in a way that optimizes their strengths (Thomas, et al., 2010). Because they autonomously attain their goals, their psychological needs are satisfied. This need satisfaction makes them more willing to engage in organizational citizenship behaviors (Greguras \& Diefendorff, 2010), and there is a negative relationship between these extra-role behaviors and burnout (Akavar-Ahmadi, Ahmadi, \& Taureh, 2011).

In addition to higher performance, proactive employees derive a sense of personal meaning from their jobs which lessens burnout (Savicki, 2002). Further, proactive individuals report high job satisfaction and life satisfaction. They pursue their self-set goals so they experience higher psychological need satisfaction with increased happiness (Greguras \& Diefendorff, 2010). Tamini and Kord (2011) found that job satisfaction and life satisfaction were negatively associated with the emotional exhaustion and depersonalization components of burnout.

Because of their factors associated with high self-efficacy, exceptional in-role/extra-role performance, and high job/life satisfaction, it is expected that proactivity will be negatively related to burnout. Therefore, the following hypothesis is offered:

Hypothesis 3: Proactivity is negatively associated with burnout.

Burnout results in increased turnover cognitions (Babakus, Yavas, \& Ashill, 2011), and it is predicted in this study that burnout will be lower for employees with proactive personalities because they 
make changes in the workplace to lessen the stress. Therefore, proactive individuals should have decreased thoughts about leaving their jobs and organizations.

When the employee can make modifications the workplace, a compatible environment can be created (Sutarjo, 2011). With this good person-organization fit, the employee feels congruence with the nature and goals of the company (Kristof-Brown, Zimmerman, \& Johnson, 2005). Because proactive individuals are capable of changing their current work environment to fit them, they often feel involved and identify with their organizations which results an affective organizational commitment, an emotional attachment to the organization (Thomas et al., 2010). Models of turnover include affective organizational commitment as an independent variable that results in lower intent to leave the organization. These models also indicate that high job satisfaction also will result in employees wanting to remain members of the organization (e.g., Price \& Mueller, 1981). Proactive employees are autonomous and prefer tasks significant to them which results in higher job satisfaction (Ambrose \& Kulik, 1999) and subsequently lower turnover intentions (Fairlie, 2011).

Therefore, it is predicted, that because of high satisfaction and organizational commitment as well as low burnout, proactivity will be associated with lower job withdrawal intentions.

Hypothesis 4: Proactivity is negatively associated with job withdrawal intentions.

\section{Method}

Employees in nonprofit organizations in the southeastern United States were surveyed during the summer 2010. Executive directors and/or CEOs of nonprofit organizations in a southeastern state in the United States working primarily in the health and human services sector by providing direct care to patients and/or clients were contacted regarding their interest in participating in the research study. The researchers requested that the Executive Director/CEO distribute the electronic survey to employees in the targeted group via email. The two-part questionnaire included the following components: (1) the Quality of Life: Compassion Satisfaction and Fatigue Subscales, R-IV (ProQOL) that was developed by Stamm (2005) and (2) a 34-item questionnaire covering related topics such as proactive personality, job withdrawal intentions, and work-group cohesion. The survey instrument was sent to approximately fifty executive directors and/or CEOs. These individuals were asked to distribute the electronic survey link to those in their organizational network (target population) who met the research criteria. The researchers determined that 271 individuals started the online survey and 242 completed the entire survey (89.3\%). All responses were anonymous.

Respondents were asked to select one category from a list provided that would accurately describe their organization and/or the population that they serve. The highest ranking categories included medical (16\%), family and children (11.4\%), health (9.4\%), disabilities (7\%) and human services (7\%). The setting for work of the respondents was overwhelmingly urban with only $35 \%$ indicating that they were servicing clients and/or patients in a rural setting. The results also indicated that information was collected from an educated work force with $23 \%$ reporting their highest level of education was a master's degree, $46 \%$ a college degree, and $8 \%$ had done some graduate work. The majority of the respondents were female $(87 \%)$.

\section{Measures}

\section{Proactive Personality}

Proactive personality was measured by a 6-item scale (alpha coefficient $=.80$ ) reported to be valid across cultures (Claes, Beheydt, \& Lemmens, 2005). A sample item in this measure is "I am always looking for better ways to do things."

\section{Work-Group Cohesion}


Work-group cohesion was tapped using a four-item measure (alpha coefficient $=.84$ ) adapted from Price \& Mueller (1981). A sample item is "I trust the members of my immediate work group."

\section{Compassion Satisfaction}

Compassion satisfaction was measured using ten items (alpha coefficient $=.92$ ) from Stamm's (2005) ProQOL instrument. A sample item is "I get satisfaction out of being able to help people."

\section{Burnout}

Burnout, assessing hopelessness in doing one's work, was measured using 10 items (alpha coefficient $=.75$ ) developed by Stamm $(2005)$. One of the statements to which subjects responded was "I feel worn out because of my work."

\section{Job Withdrawal Intentions}

Job withdrawal intentions was gauged using three items (alpha coefficient $=.89$ ) from Michaels and Spector's measure (1982). One of the three items is, "I think often about quitting this job."

\section{Results}

The correlations among the constructs were examined. Both work-group cohesion (Hypothesis 1 ) and compassion satisfaction (Hypotheses 2 ) were positively related to proactive personality $(r=.32, p \leq$ .01 and $r=.47, p \leq .01$, respectively). The negative relationships between proactive personality and burnout $(r=-.18, p \leq .01)$ and proactive personality and job withdrawal intentions $(r=-.20, p \leq .01)$ provided initial support for predicted Hypotheses 3 and 4. Table 1 reports the inter-correlations among the study variables along with other descriptive statistics.

Table 1

Model Correlations and Descriptive Statistics

\begin{tabular}{|l|l|c|c|c|c|c|c|c|}
\hline \multicolumn{2}{|c|}{} & Mean & SD & WGC & CS & BU & JWI & PAP \\
\hline $\begin{array}{l}\text { Work Group } \\
\text { Cohesion }\end{array}$ & $\begin{array}{l}\text { Pearson } \\
\text { Correlation }\end{array}$ & 4.05 & 0.73 & $\mathbf{( . 8 4 )}$ & $.317^{* *}$ & $-.271^{* *}$ & $-.471^{* *}$ & $.322^{* *}$ \\
\hline $\begin{array}{l}\text { Compassion } \\
\text { Satisfaction }\end{array}$ & $\begin{array}{l}\text { Pearson } \\
\text { Correlation }\end{array}$ & 4.90 & 0.82 & & $\mathbf{( . 9 2 )}$ & $-.622^{* *}$ & $-.476^{* *}$ & $.476^{* *}$ \\
\hline Burnout & $\begin{array}{l}\text { Pearson } \\
\text { Correlation }\end{array}$ & 2.54 & 0.71 & & & $\mathbf{( . 7 5 )}$ & $.603^{* *}$ & $-.175^{* *}$ \\
\hline $\begin{array}{l}\text { Job Withdrawal } \\
\text { Intentions }\end{array}$ & $\begin{array}{l}\text { Pearson } \\
\text { Correlation }\end{array}$ & 2.37 & 1.07 & & & & $\mathbf{( . 8 9 )}$ & $-.201^{* *}$ \\
\hline $\begin{array}{l}\text { Proactive } \\
\text { Personality }\end{array}$ & $\begin{array}{l}\text { Pearson } \\
\text { Correlation }\end{array}$ & 3.83 & 0.61 & & & & & $\mathbf{( . 8 0 )}$ \\
\hline
\end{tabular}

$\mathrm{N}=242$

* Cronbach alpha reliabilities for observed variables are in parenthesis in the diagonal.

** Correlation is significant at the 0.01 level (2-tailed).

To test the hypothesized model, confirmatory PLS Structural Equation Modeling was performed with proactive personality as the antecedent variable using Smart PLS 2.0 software for the analysis. PLSSEM is a causal modeling approach intended to maximize explained variance of the dependent latent 
constructs (Hair, Ringle, and Sarstedt 2011; Hair, Black, Babin, \& Anderson, 2010). In comparison, covariance-based SEM seeks to reproduce the theoretical covariance matrix without focusing on explained variance. PLS-based SEM has been increasingly used in business disciplines, and it has benefits not offered by CB-SEM that are important to this study. First, it is a preferred method for prediction and theory development (Hair et al., 2011). Second, PLS-SEM has an ability to work effectively with smaller sample sizes (Chin, 2010; Chin, \& Newsted 1999; Joreskog \& Wold 1982). Finally, PLS-SEM is also a well established method for investigating cause-effect relationships in business research (Gudergan, Ringle, Wende, \& Will, 2008).

The PLS-SEM model showed that all four paths were above the PLS modeling threshold (.20) for significance: work-group cohesion $($ path coefficient $=.34)$, compassion satisfaction $($ path coefficient $=$ .49 ), burnout (path coefficient $=-0.47$ ), and job withdrawal intentions (path coefficient $=-.22$ ). The results of the PLS-SEM analysis are shown in Figure 1.

Figure 1: The PLS-SEM Model

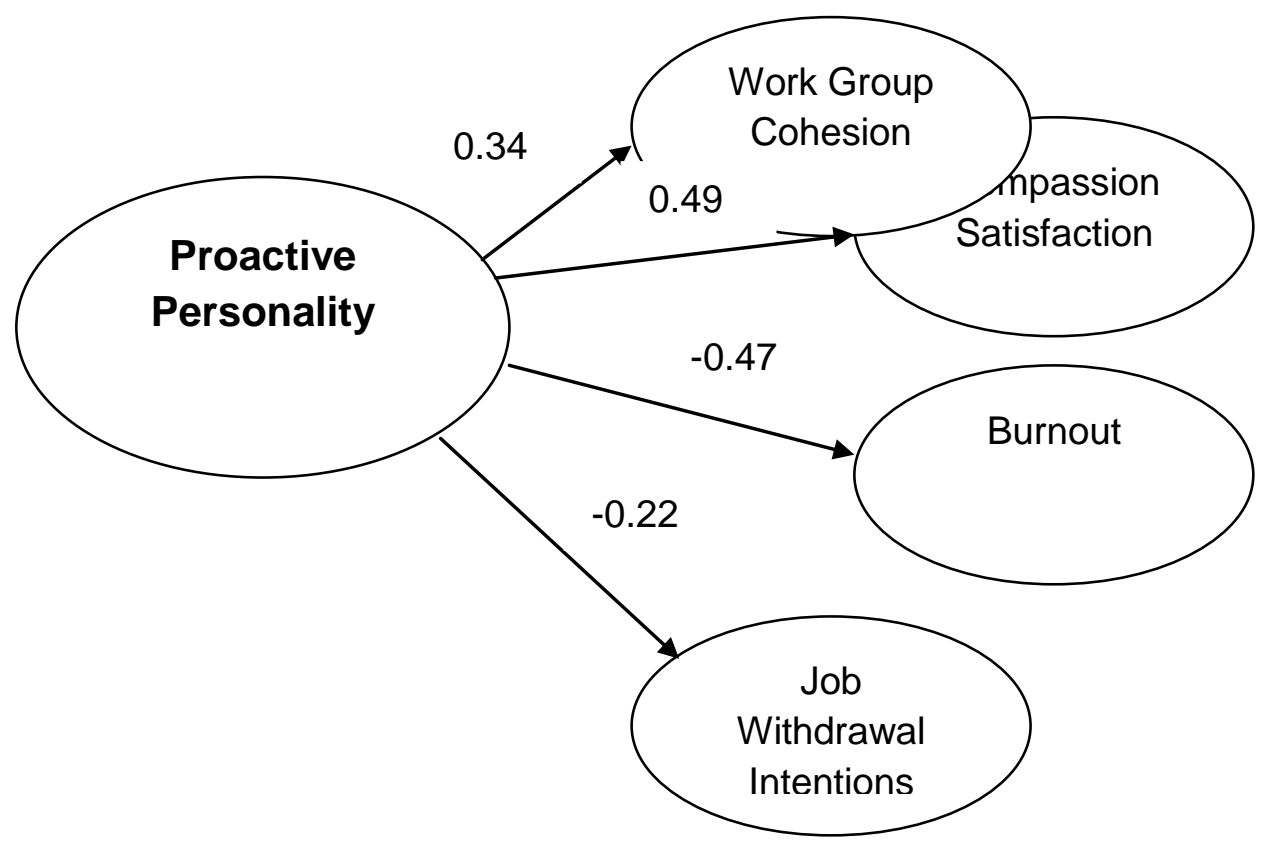

Discussion

This study has expanded the positive personal and organizational outcomes associated with proactivity. However, there are limitations of this research that need to be considered. First, the survey distribution method used by the researchers did not allow for determination of a specific response rate. Further, the researchers do not know whether non-respondents are less proactive than respondents, though one would suspect that they are. Next, the sample in this study was predominantly female which may impact findings. For example, the tendency of women to be more empathic than men (Toussaint, \& Webb, 2005) may influence the compassion satisfaction outcome. Finally, to extend the generalizability of the current findings, research needs to be expanded beyond non-profit employees as it is possible that these service providers are more proactive because of the perceived meaningful nature of their work as compared to for-profit employees.

Though significant, the hypothesis suggesting a negative relationship between proactivity and job withdrawal intentions was the weakest path in the casual model. Perhaps one reason this was only slightly above the significance threshold is that these talented employees will be attracted to other companies because of lucrative offers (Krell, 2012). Also, proactive employees prefer a protean career 
path in which they make frequent adjustments in their line of work. Like many others, proactive individuals can no longer count on staying with one organization throughout their lives. Instead, they must modify their jobs and change companies many times during their work lives in order to promote their careers. Essentially, they must become boundaryless, and are not tied to organizations (Hall, 1996). Proactive employees do this effectively because they are adaptable, autonomous, and eager learners. They select, create, and change their work environment so that they can improve their careers (Seibert et al., 2001).

There is another, less positive, reason for why proactive employees may not have high intentions to remain in the organization. Proactivity is not always valued by supervisors. When employees voice their concerns about problems and challenge others to change, managers may feel threatened because of the perception that these proactive employees are attempting to usurp their power (Chan, 2006).

However, attributions by the supervisor are varied. Sometimes the supervisor may believe that the employee is being ingratiating (Morrison \& Milliken, 2000), or that the employee is being critical rather than offering constructive criticism (Grant et al., 2009). Other managers see this behavior as a distraction (Detert \& Burris, 2007). When proactive employees voice their concerns, it ultimately can have a negative effect on salary growth and number of promotions which propels them to find another organization (Seibert et al., 2001).

If organizations need to respond to change, managers should embrace and reinforce the proactive employee. Experienced leaders often tolerate challenges from employees. They are willing to share power with employees and be receptive to their ideas. They spend time listening to employees rather than promoting one's own agenda. Instead of being defensive about suggestions, leaders recognize that two heads are often better than one (Sloan \& Pollak, 2006). An organizational culture that encourages communication and avoids intimidation tactics allows employees to discuss issues relevant to the mission. Even when the employee's suggestion is not quite accurate, an internal environment where employees can speak their mind about problems can lead to innovative solutions (Grant et al., 2011).

In summary, in complex environments, managers depend on employees to have bottom-up solutions so that threats and opportunities can be anticipated and acted upon (Van Dyne \& Lepine, 1988). Employees must be willing and able to challenge the status quo so that the organization is more adaptive. Proactive employees do just that. They not only voice their concerns but take responsibility for making the needed changes, and they often solve the problem in an innovative way (Parker et al., 2006). If management is supportive of the proactive employee, there are many positive benefits for the individual and the organizations. This study expands these outcomes to include high work-group cohesion, high compassion satisfaction, low burnout, and low job withdrawal intentions.

\section{References}

Akavar-Ahmadi, S. A., Ahmadi, F., \& Tavreh, N. (2011). The relationship between organizational citizenship behavior and burnout in public organization in west Azarbayejan province. Interdisciplinary Journal of Contemporary Research in Business, 2(11), 147-156.

Ambrose, M. L., \& Kulik, C. T. (1999). Old friends, new faces: Motivation research in the 1990s. Journal of Management, 25, 231-292.

Babakus, E., Yavas, U., \& Ashill, N. J. (2011). Service worker burnout and turnover intentions: Roles of person-job fit, servant leadership, and customer orientation. Service Marketing Quarterly, 32(1) $17-31$.

Bateman, T. S., \& Crant, J. M. (1993). The proactive component of organizational behavior: A measure and correlates. Journal of Organizational Behavior, 14, 103-118.

Chan, D. (2006). Interactive effects of situational judgment effectiveness and proactive personality on work perceptions and work outcomes. Journal of Applied Psychology, 91, 475-481.

Chin, W. W. (2010). How to write up and report PLS analyses. In V.Esposito et al. (Eds.), Handbook of partial least squares: Springer handbooks of computational statistics (pp. 655-688). Berlin Heidelberg: Springer-Verglag. 
Chin, W. W., \& Newsted, P. R. (1999). Structural equation modeling analysis with small samples using partial least squares. In R. Hoyle (Ed.), Statistical strategies for small sample research (307341). Thousand Oaks, CA: Sage.

Claes, R., Beheydt, C. \& Lemmens, B. (2005). Unidimensionality of abbreviated proactive personality scales across cultures. Applied Psychology: An International Review, 54, 476-489.

Crant, J. M. (1995). The proactively scale and objective performance among real estate agents. Journal of Applied Psychology, 80, 532-537.

Crant, J. M. (2000). Proactive behavior in organizations, Journal of Management, 26, 435-462.

David, E., \& Vivik, P. (2012). Exploring the relationship between organization-based self esteem and burnout: A preliminary analysis. Advances in Management, 5(3), 54-58.

Detert, J. R., \& Burris, E. R. (2007). Leadership behavior and employee voice: Is the door really open? Academy of Management Journal, 50, 869-884.

Dutton, J. E., Ashford, S. J., O’Neill, R. M., \& Lawrence, K. A. (2001). Moves that matter: Issue selling and organizational change. Academy of Management Journal, 44, 716-736.

Erdogan, B., \& Bauer, T. N. (2005). Enhancing career benefits of employee proactive personality: The role of fit with jobs and organizations. Personnel Psychology, 58, 859-891.

Fairlie, P. (2011). Meaningful work, employment engagement, and other key employee outcomes: Implications for human resource development. Advances in Developing Human Resources, 13(4), 508-525.

Frese, M. Fay, D., Hilburger, T. Leng, K., \& Tag, A. (1997). The concept of personal initiative: Operationalization, reliability, and validity in two German samples. Journal of Occupational and Organizational Psychology, 70, 139-161.

Grant, A. M., Gino, F., \& Hofmann, D. A. (2011). Reversing the extraverted leadership advantage: The role of employee proactivity. Academy of Management Journal, 54, 528-550.

Grant, A. M., Parker, S., \& Collins, C. (2009). Getting credit for proactive behavior: Supervisor reactions depend on what you value and how you feel. Personnel Psychology, 62, 31-55.

Grant, A. M., \& Patil, S. V. (2012). Challenging the norm of self-interest: Minority influence and transitions to helping norms in work units. Academy of Management Review, 37(4), 547-568.

Greguras, G. J., \& Diefendorff, J. M. (2010). Why does proactive personality predict life satisfaction and work behaviors? A field investigation of the mediating role of the self-concordance model. Personnel Psychology, 63, 539-560.

Griffin, M. A., Neal, A., \& Parker, S. K., (2007). A new model of work role performance: Positive behavior in uncertain and interdependent contexts. Academy of Management Journal, 50, 327 347.

Gudergan, S. P., Ringle, C. M., Wende, S., \& Will, A. (2008). Confirmatory tetrad analysis in PLS modeling. Journal of Business Research, 61, 1238-1249.

Hackman, J. R., \& Oldham, G. R. (1975). Development of a job diagnostic survey. Journal of Applied Psychology, 60, 159-170.

Hair, J., Black, W. C., Babin, B. J., \& Anderson, R. E. (2010), Multivariate data analysis. Upper Saddle River, NJ: Pearson Prentice Hall.

Hair, J., Ringle, C.M., \& Sarstedt, M. (2011). PLS-SEM: Indeed a silver bullet. Journal of Marketing Theory and Practice, 19(2), 139-151.

Hall, D. T. (1996). Protean careers of the $21^{\text {st }}$ century. Academy of Management Executive, 10, 8-16.

Joreskog, K.G., \& Wold, H. (1982) The ML and PLS techniques for modelling with latent variables: Historical and comparative aspects. In K. G. Jöreskog \& H. Wold (Eds.), Systems under indirect observation: Causality, structure, prediction (Vol. 1, pp. 263-270). Amsterdam: North-Holland.

Keidel, G. (2002). Burnout and compassion fatigue among hospice caregivers. American Journal of Hospice \& Palliative Care, 19(3), 200-205.

Kidwell, R. E., Mossholder, K. W., \& Bennett, N. (1997). Cohesiveness and organizational citizenship behavior: A multilevel analysis using work groups and individuals. Journal of Management, 23(6) 775-794. 
Krell, E. (2012). 5 ways to manage high turnover. HR Magazine, 57(4) 63-65.

Kristof-Brown, A. L., Zimmerman, R. D., \& Johnson, E. C. (2005). Consequences of individuals' fit at work: A meta-analysis of person-job, person-organization, person-group, and person-supervisor fit. Personnel Psychology, 58(2), 281-342.

Lawson, G., \& Myers, J. E. (2011). Wellness, professional quality of life and career-sustaining behaviors: What keeps us well? Journal of Counseling \& Development, 89, 163-171.

Loh, J., Smith, J. R., \& Restubog, S. L. D. (2010). The role of culture, workgroup membership, and organizational status on cooperation and trust: An experimental investigation. Journal of Applied Social Psychology, 40(12), 2947-2968.

Mach, M., Dolan, S., \& Tzafrir, S. (2010). The differential effect of team members' trust on team performance: The mediation role of team cohesion. Journal of Occupational and Organizational Psychology, 83, 771-794.

Maslach C. (1982). Burnout, the Cost of Caring. Englewood Cliffs, NJ: Prentice Hall.

Maslach, C., \& Jackson, S. E. (1984). Burnout in organizational settings. Applied Social Psychology Annual, 5, 133-135.

Michaels, C., \& Spector, P. (1982). Causes of employee turnover: A test of the Mobley, Griffeth, Hand and Meglino model. Journal of Applied Psychology, 67, 53-59.

Morrison, E. W., \& Milliken, F. J. (2000). Organizational silence: A barrier to change and development in a pluralistic world. Academy of Management Review, 25, 706-725.

Morrison, E. W., \& Phelps, C. (1999). Taking charge: Extra-role efforts to initiate workplace change. Academy of Management, 42, 403-419.

Ng, K. Y., \& Van Dyne, L. (2005). Antecedents and performance consequences of helping behavior in work groups. Group \& Organization Management, 30(5), 514-540.

Ohly, S., \& Fritz, C. (2007). Challenging the status quo: What motivates proactive behavior? Journal of Occupational \& Organizational Psychology, 80(4), 623-629.

Parker, S. K., Williams, H. M., \& Turner, N. (2006). Modeling the antecedents of proactive behavior at work. Journal of Applied Psychology, 91, 636-652.

Petitta, L, \& Vecchione, M. (2011). Job burnout, absenteeism, and extra role behaviors. Journal of Workplace Behavioral Health, 26(2), 97-121.

Pierce, J. L., Gardner, D. G., Cummings, L. L. \& Dunham, R. B. (1989). Organization-based self-esteem: Construct definition, measurement, and validation. Academy of Management Journal, 32(3), 622-648.

Prati, G., Pietrantoni, L., \& Cicognani, E. (2010). Self-efficacy moderates the relationship between stress appraisal and quality of life among rescue workers. Anxiety, Stress, \& Coping, 23(4), 463-470.

Price, J. L. (1997). Handbook of organizational measurement. International Journal of Manpower, 18, 305-558.

Price, J. L., \& Mueller, C. W. (1981). A casual model of turnover for nurses. Academy of_Management Journal, 24, 543-565.

Rady, M., \& Figley, C. R. (2007). The social psychology of compassion. Clinical Social Work Journal, $35,207-214$.

Savicki, V. (2002). Burnout across Thirteen Cultures: Stress and Coping in Child and Youth Care Workers. Westport, CN: Praeger.

Seibert, S. E., Kraimer, M. L., \& Crant, J. M. (2001). What do proactive people do? A longitudinal model linking proactive personality and career success. Personnel Psychology, 54(4), 845-874.

Shamir, B. (1990). Calculations, values, and identities: The sources of collectivistic work motivation. Human Relations, 43, 313-332.

Shin, Y., \& Choi, J. N. (2010). What makes a group of good citizens? The role of perceived group-level fit and critical psychological states in organizational teams. Journal of Occupational and Organizational Psychology, 83, 531-552.

Slatten, L. A., Carson, K. D., Carson, P. P. (2011). Compassion fatigue and burnout: What managers should know. Health Care Manager, 30, 325-333. 
Sloan, K. \& Pollak, L. (2006). Smarter, Faster, Better: Strategies for Effective, Enduring, \& Fulfilled Leadership. San Francisco: Jossey-Bass.

Stamm, B. H. (2005). Professional quality of life: compassion satisfaction and fatigue subscales, $R-I V$ (ProQOL). http://www.isu.edu/ bhstamm.

Stroebe, W., \& Frey, B. S. (1982). Self-interest and collective action: The economics and psychology of public goods. British Journal of Social Psychology, 21, 121-137.

Sutarjo, X. (2011). Ten ways of managing person-organization fit (p-o fit) effectively: A literature study. International Journal of Business and Social Science, 2(21), 226-233,

Tamini, B. K., \& Kord, B. (2011). Burnout components as predictors of job \& life satisfaction of university employees. Indian Journal of Industrial Relations, 47(1), 126-137.

Thomas, J. P., Whitman, D. S., \& Viswesvaran, C. (2010). Employee proactivity in organizations: A comparative meta-analysis of emergent proactive constructs. Journal of Occupational and Organizational Psychology, 83, 275-300.

Thompson, J. A. (2005). Proactive personality and job performance: A social capital perspective. Journal of Applied Psychology, 90(5), 1011-1017.

Toussaint, L., \& Webb, J. R. (2005). Gender differences in the relationship between empathy and forgiveness. Journal of Social Psychology, 145(6) 673-685.

Vaill, P. B. (2007). F. J. Roethlisberger and the elusive phenomena of organizational behavior. Journal of Management Education, 31, 321-338.

Van Dyne, L., \& LePine, J. A. (1998). Helping and voice extra-role behaviors: Evidence of construct and predictive validity. Academy of Management Journal, 41, 108-119.

van Woerkom, M., \& Sanders, K. (2010). The romance of learning from disagreement: The effect of cohesiveness and disagreement on knowledge sharing behavior and individual performance within teams. Journal of Business Psychology, 25, 139-149. 